\title{
The Early Phase of Vascularization in Intraocular Telencephalic Transplants
}

\author{
Andrea Tuba and Mihály Kálmán \\ Department of Anatomy, Histology, and Embryology, Semmelweis University of Medicine, \\ Budapest, Hungary, H-1450
}

\section{SUMMARY}

The present study focused on the early events of vascularization of intraocular cerebral transplants. Telencephalic pieces of rat embryos (E15) were transplanted into the anterior eye chamber of adult rats in deep ketamine-xylazine narcosis. At 3-, 4-, 5-, 6-, or 7-day postoperative survival periods, the rats were perfused and the transplants, with their iridic beds, were processed into serial, semi-thin sections. In 3and 4-day transplants, neither dilated (perfused) nor collapsed blood vessels were found, but tissue defects, without proper wall and filled by non-nucleated (mature, host) erythrocytes, were seen. On post-operative day 5 , large sinusoids were seen lines by endothel and free of blood cells (as a consequence of perfusion). On days 6 and 7 , the usual, although large, blood vessels were found. Our results suggest that the critical period of transplant vascularization is between postoperative days 4 and 5 , and that the original vessels of donor tissue degenerate and disappear during the first postoperative days and thus, do not participate directly in transplant vascularization. Our hypothesis is that vascular invasion begins with the opening of host blood vessels into clefts formed by degeneration of graft tissue. For a period, a hemostasis occurs in these blood-filled lacunae, and then endothel invasion from host vessels forms the proper wall. The transplant vasculature develops from these

\footnotetext{
Reprint address:

Mihály Kálmán

Department of Anatomy, Histology, and Embryology,

Semmelweis University of Medicine

Tüzoltó 58, Budapest, Hungary, H-1450.

Fax: +36-1-215-5158
}

large sinusoids. The results challenge the role of the pre-existing donor vessels in transplant vascularization. A possible explanation of such paradoxical results is that the donor tissue must reach a stage of maturation to receive the ingrowing vessels, either host vessels, and the presence of vessels in the donor brain is the sign of this stage of maturation but has no direct role in transplant vascularization

\section{KEY WORDS}

neurotransplantation, cerebral transplant,

\section{INTRODUCTION}

As clinical results can be expected only in cases of long-surviving transplants, most data (see $/ 2,4,17 /$ for reviews) have been published on transplants that survived for longer periods. The early postoperative events, however, are crucial for transplant survival. The present study focuses on the early events of vascularization in intraocularly transplanted rat telencephalon.

Although vascularization is a critical factor for transplant survival, no consensus regarding its mechanism can be found in the literature. One suggestion is that the intrinsic vessels, which preexisted in the donor tissue before transplantation, persist in the transplant and form connections with the ingrowing host vessels $/ 1,5,11-13,16,17 /$. Actually, the lower edge of the time-window in which the developing brain is competent for transplantation (for reviews see $/ 2,4,17 /$ ) approximately coincides with the beginning of brain vascularization in situ. According to an opposite theory, the original vasculature of the donor tissue disappears after transplantation, and the definitive 
vasculature is formed by the ingrowing host vessels as a completely new system $/ 14,18,20 /$.

Our previous results $/ 9,19 /$ seemed to support the importance of pre-existing donor vessels in transplant survival because the survival ratio increased strikingly with the stage of the vascularization of the donor brain. The present study, however, follows the day-by-day vascularization of the intraocularly transplanted rat embryonic telencephalon and demonstrates the disappearance of donor vessels from the transplant before its vascularization by host vessels.

\section{METHODS}

To obtain dated embryos, we prepared vaginal smears from female albino CFY (Carworth Farm Y, Gödölló, Hungary) rats that had mated with male rats overnight. The day of sperm-positivity was considered as E0. At E15, the embryos were removed from the mother in deep ketamine-xylazine narcosis $(20 \mathrm{mg} / \mathrm{kg}$ and $80 \mathrm{mg} / \mathrm{kg}$ body weight, respectively), and samples of their neopallium were immediately dissected out. Adult recipient rats (CFY strain) were anesthetized as described above and premedicated with atropine. The cornea was incised with a sterile blade, and the embryonic tissue sample was placed into the anterior eye chamber using a sterile cannule. After 3-, 4-, 5-, 6-, and 7-day postoperative survival periods, the recipient animals were overdosed with diethylether and perfused transcardially with $0.9 \%$ sodium chloride followed by Karnovsky fixative /10/. Each transplant with its iridic bed was dissected out and embedded into epoxy resin (Durcupan, Fluka), cut with an ultra-microtome into serial semi-thin sections, and then stained with toluidine blue. To check the quality of the final transplant structure, some recipients were allowed to survive for 30 days. Tissue samples of E15 telencephalon were similarly processed into semi-thin sections.

\section{RESULTS}

Figure 1 shows that transplants surviving for 30 days showed both advanced neural differentiation and rich vascularization. The neurons were well- differentiated, had loose nuclei and conspicuous Nissl-substance. Clusterization of neurons was frequently seen. The distribution of astroglial cells was more even, with some attached to the neurons as satellite glial cells, and myelinated fibers were also observed. The vessels were wide open, obviously perfused with fixative, indicating that they had been connected with host circulatory system. These features proved the proper quality of our transplanted tissue.

When the early events of vascularization were followed, no blood vessels were found in the transplants on the third and fourth days after transplantation, despite the rich vascularization of the adjacent iridic tissue (Fig. 2). Within the transplant, an enormous number of degenerated and pyknotic cells appeared, and the surrounding cells phagocytized their degenerated neighbors in toto. We have previously described a similar phagocytic process in our papers on normal and irradiated neuroepithel $/ 7,8 /$.

On the fourth day, we observed in the transplants large tissue defects filled by red blood cells (Figs. 3-4). The tissue defects seemed to have no proper wall (neither endothel nor any other), as also demonstrated by electron microscopy (Fig. 5). As the erythrocytes had no nuclei, they were not fetal (residual donor) cells. The persistence of red blood cells despite the perfusion suggested (temporary) hemostasis, that is, no effective connection with the circulation of the host.

The large sinusoids of similar size observed in 5day transplants were lined by endothel and seemed to be wide but empty, evidently connected with the host vessels and perfusion had washed the blood away. We found the connection to the iridic vessels in serial sections, shown in Fig. 6. Even on the sixth and seventh days, relatively large, sinusoid-like vessels could be seen in the transplants (Figs. 7-8).

No remnant of donor vessels were found in the transplants. Even if the intrinsic graft vessels had not yet found a connection with the host vessels on the third or fourth days after transplantation and hence were not perfused, the collapsed vessels with trapped red blood cells should have been recognized, but none were found. To illustrate the phenomenon, Fig. 9 shows a detail of a 30-day transplant in which the perfusion accidentally was not effective. The E15 telencephalic tissue examined 


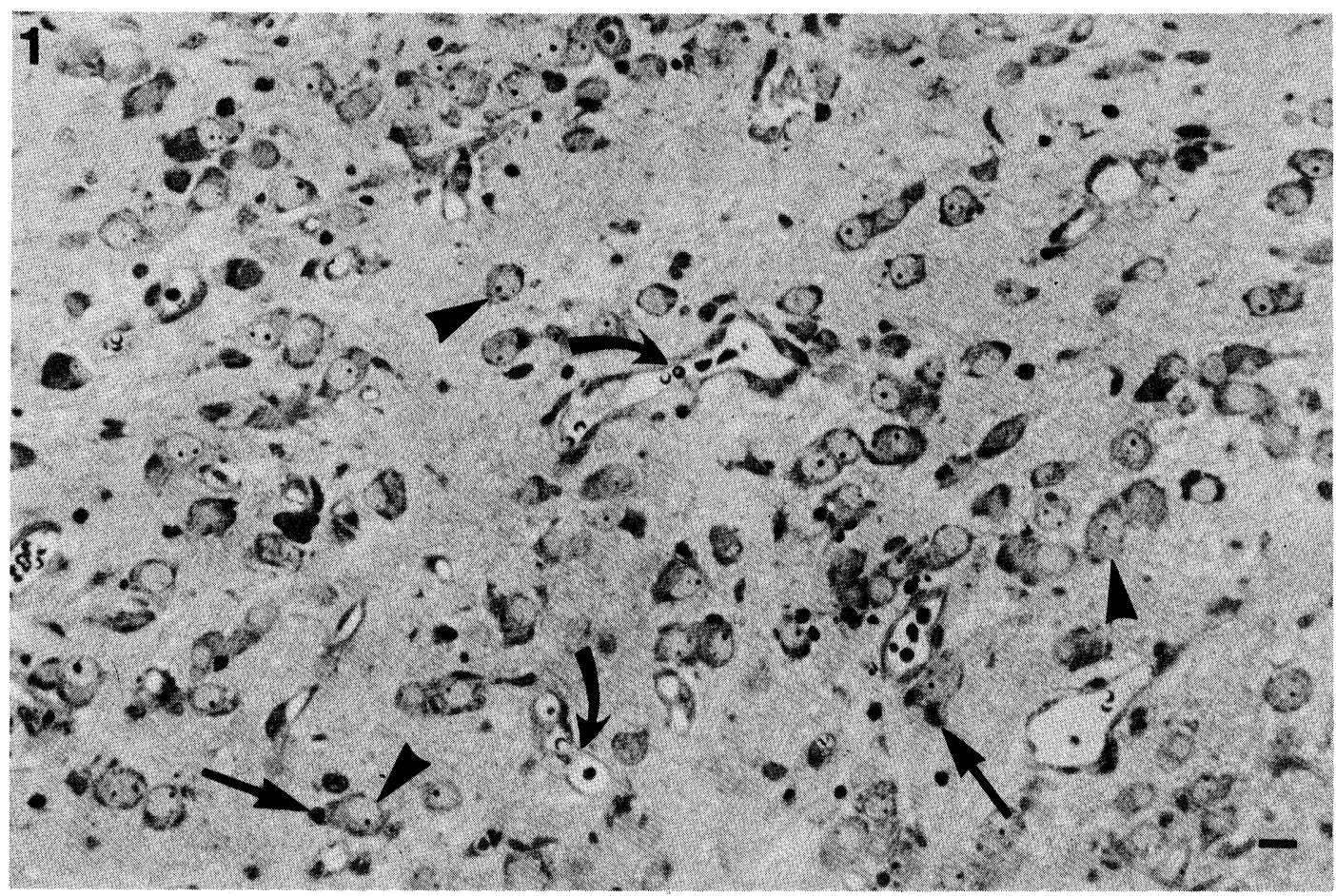

Fig. 1. E15 telencephalic tissue, one month after transplantation. Note the well-differentiated neurons (arrowheads) and the rich vascularization (curved arrows). Arrows - satellite glial cells. Bar: $30 \mu \mathrm{m}$.

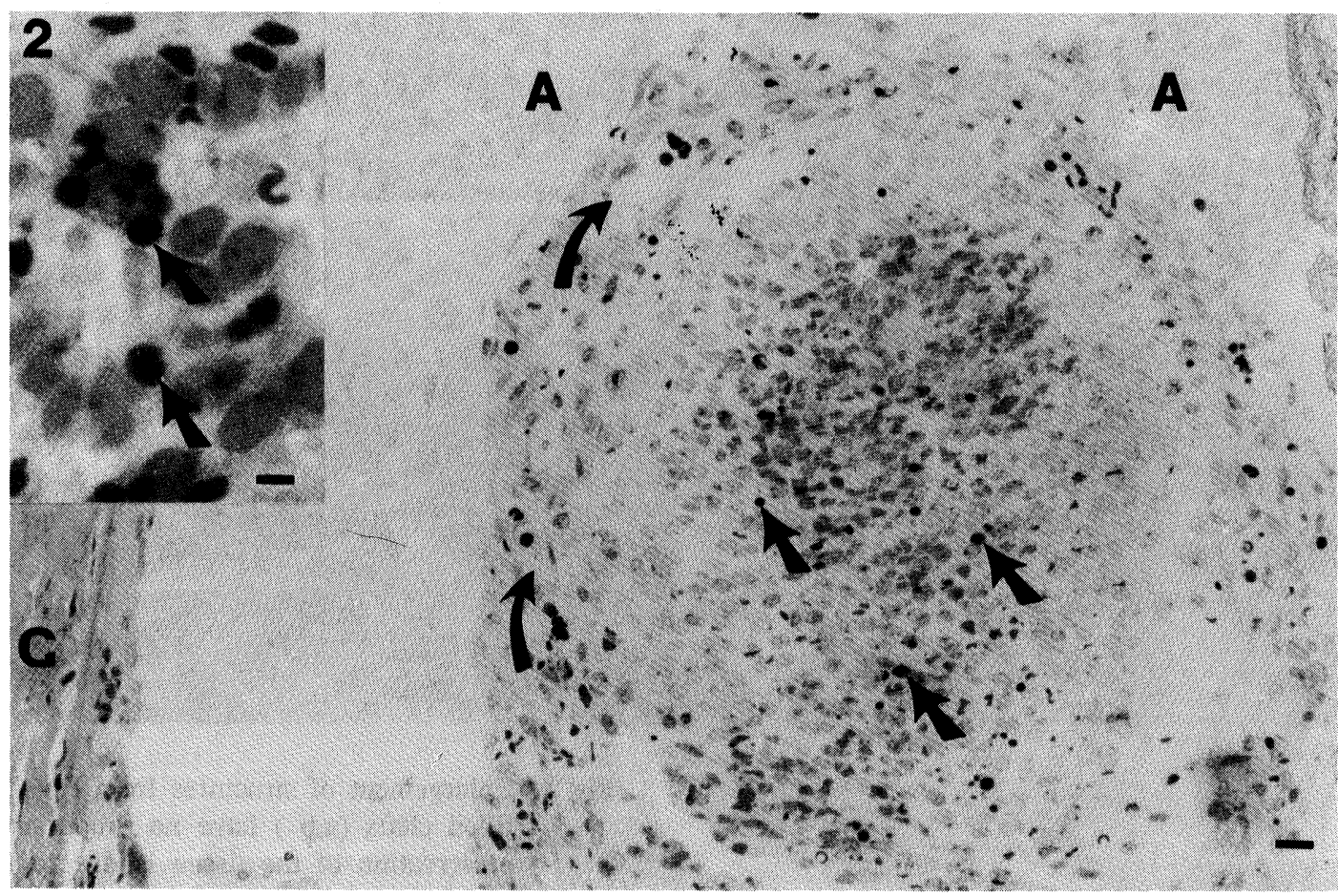

Fig. 2. E15 telencephalic tissue, third day after transplantation. No blood vessels can be found in the transplant, although the adjoining iridic tissue is richly vascularized (curved arrows). The dense particles (arrows) are remnants of degenerated and phagocytosed cells, as demonstrated in the enlarged inset. A - anterior eye chamber; C - cornea. Bar: $100 \mu \mathrm{m}$, inset bar: $10 \mu \mathrm{m}$. 


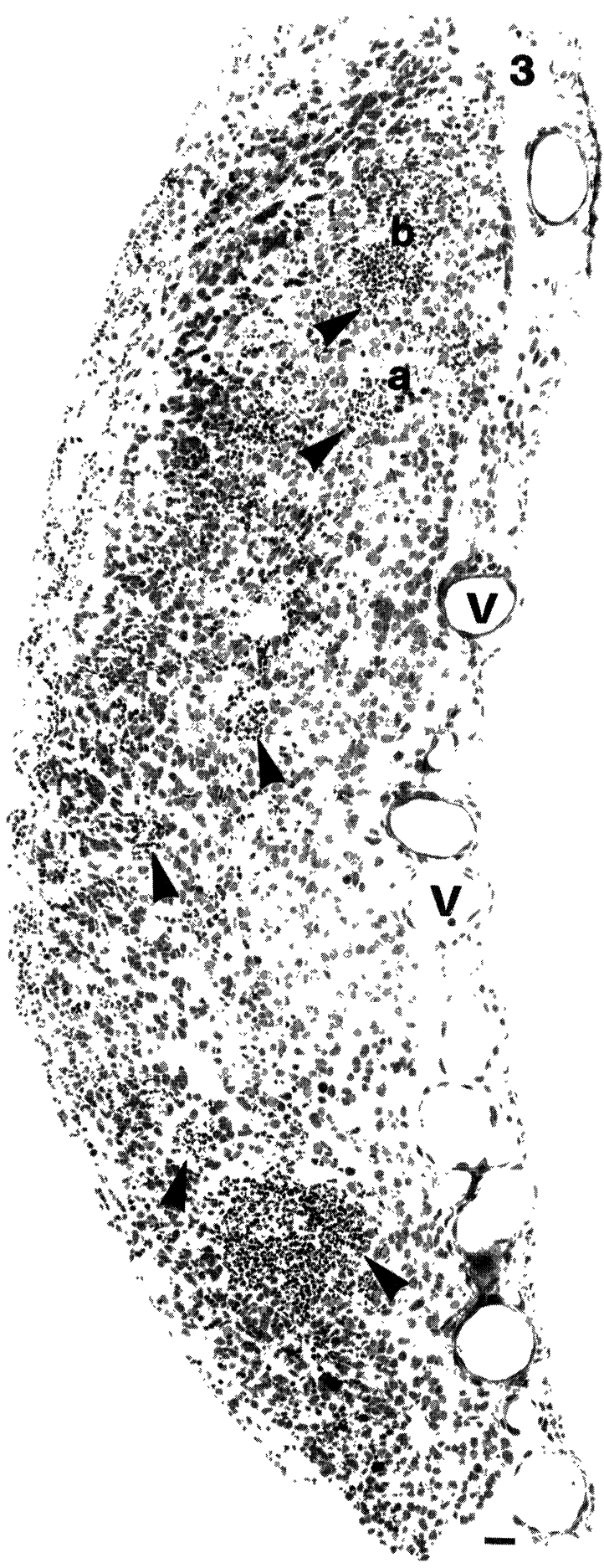

Fig. 3. Light micrograph of E15 telencephalic tissue, fourth day after transplantation. Large clefts filled by red blood cells (arrowheads) can be seen throughout. V iridic vessels; a,b, - structures enlarged in Fig. 4. Bar: $100 \mu \mathrm{m}$.

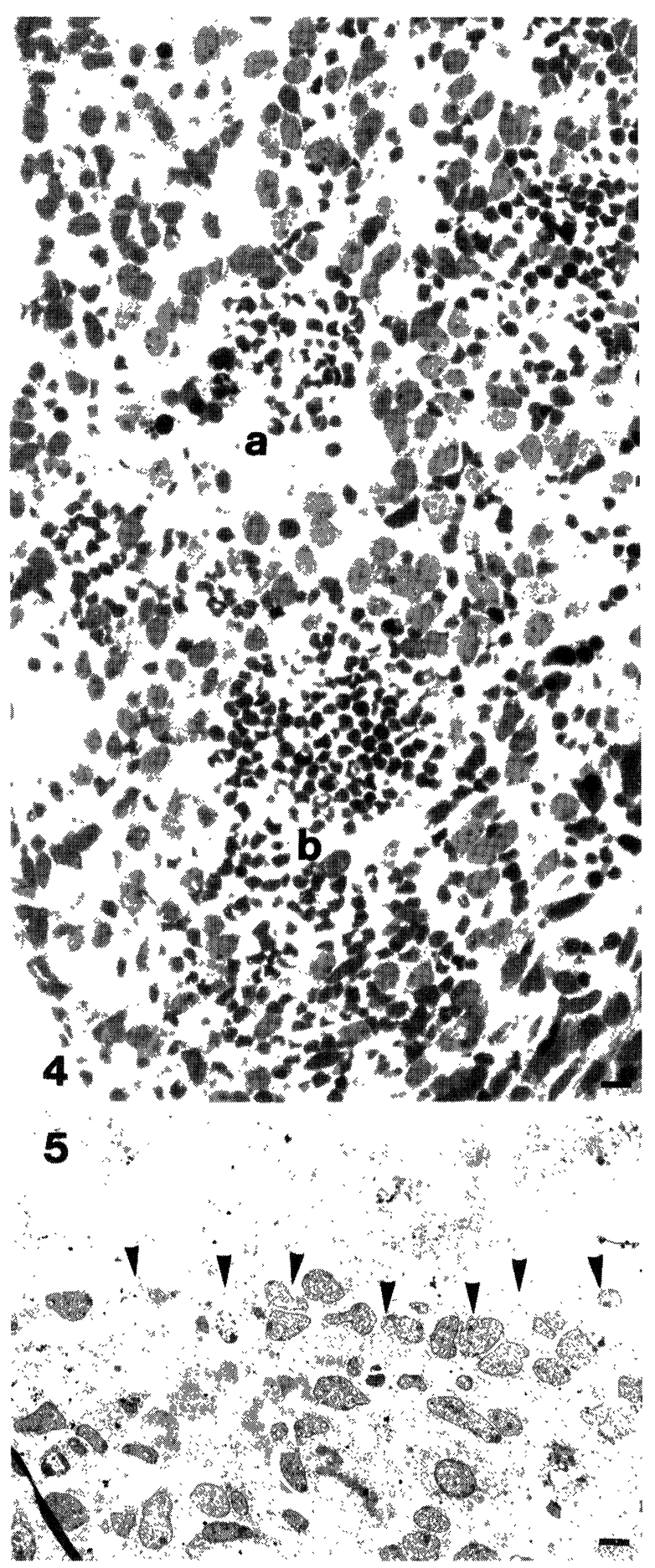

Fig. 4. Enlargement of structures from Fig. 3. The bloodfilled clefts $(a, b)$ have no proper wall. The poor preservation of the tissue is due to the inefficient circulation (in consequence: inefficient perfusion) of the transplant at this age. Compare to structure seen after longer survival periods (Fig. 1). Bar: $30 \mu \mathrm{m}$.

Fig. 5. Ultrastructure of the Sorder (arrowheads) of a cleft similar to that seen in Fig. 4. Bar: $5 \mu \mathrm{m}$.

JOURNAL OF NEURAL TRANSPLANTATION \& PLASTICITY 

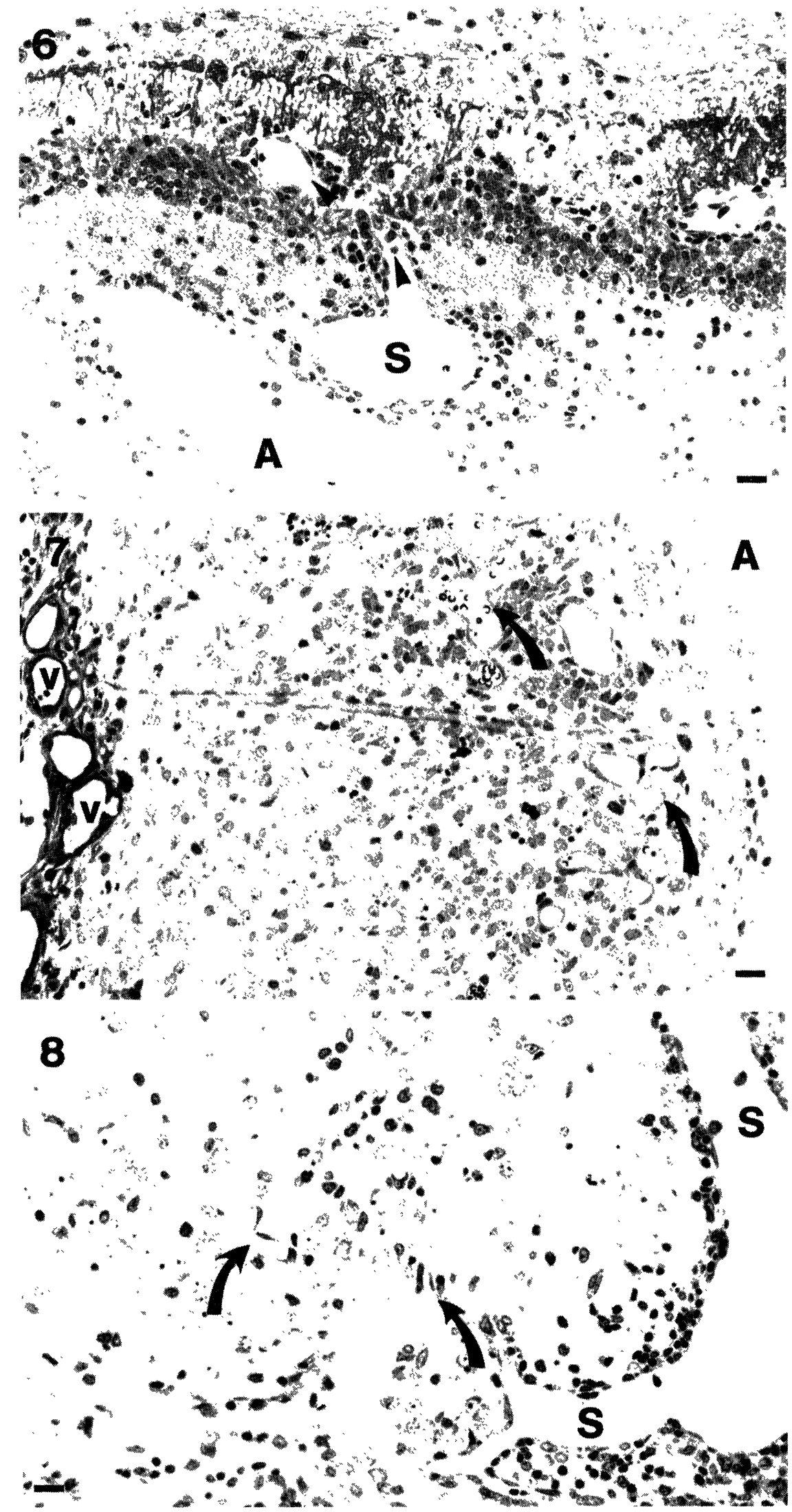

Fig. 6. Day 5 after transplantation. The photomicrograph shows a sinusoid (S) in the graft and its connection to an iridic vessel (arrowheads) as revealed by serial sectioning (not shown). Note the diameter of the sinusoid is larger than that of the connecting vessel and is similar to that of the bloodfilled spaces seen in Fig. 3. A- anterior eye chamber. Bar: $100 \mu \mathrm{m}$.

Fig. 7. Day 6 after transplantation. Relatively large vessels can be seen (curved arrows). The vessels are free of blood, proving an efficient perfusion. A - anterior eye chamber, V iridic vessels. Bar: $100 \mu \mathrm{m}$.
Fig. 8. Large sinusoid (S) lined by endothel seems to be continuing in smaller vessels (curved arrows) as though it were a transient form between the stages shown in Figs. 6 and 7. Bar: $50 \mu \mathrm{m}$. 


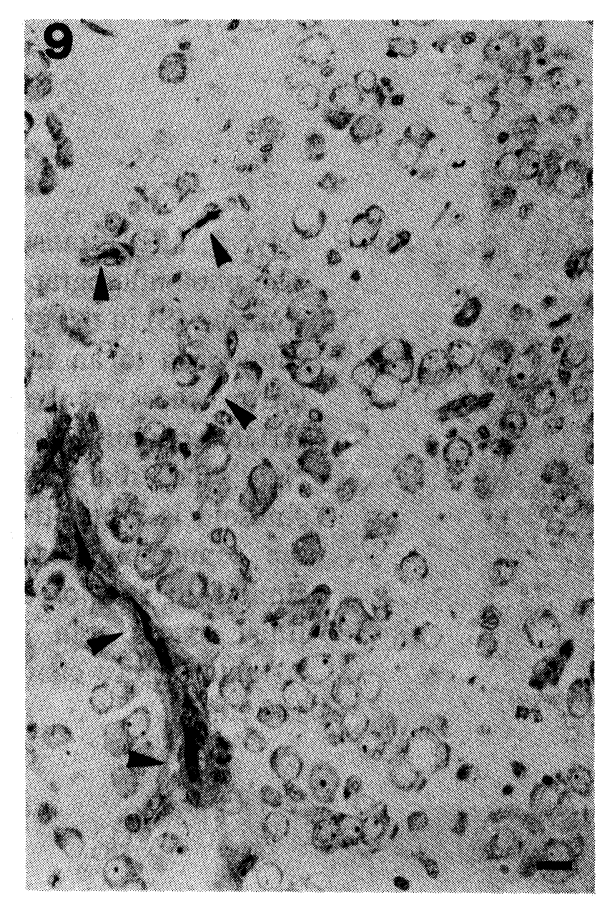

Fig. 9. Collapsed capillaries (arrowheads) in a 30-day transplant-survival period. The perfusion was not effective, and the capillaries collapsed trapping red blood cells. Similarly collapsed capillaries had been expected at the earliest stage of transplant development as remnants of the original donor vessels are not connected with the host circulation, but none were observed.

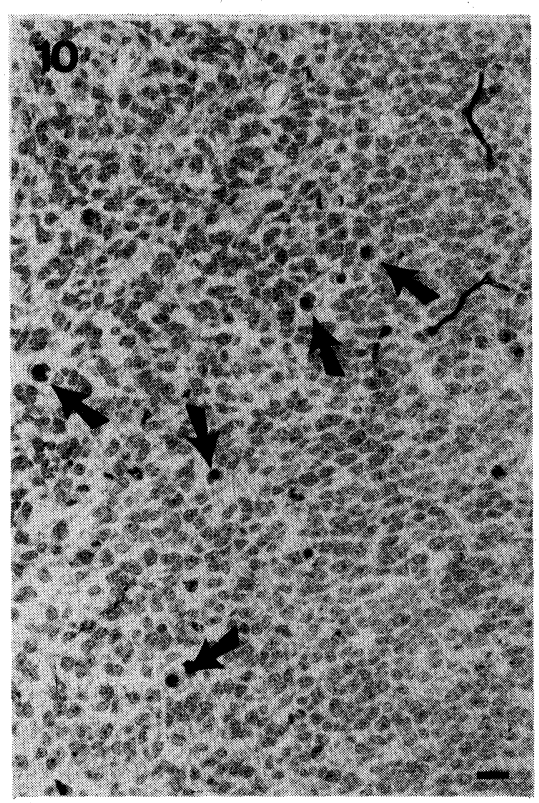

Fig. 10. E15 telencephalon in situ. See the fetal red blood cells (arrows) containing nuclei. Similar cells were not observed in the transplants. Bar: $30 \mu \mathrm{m}$. in situ proved to be vascularized, and its capillaries contained fetal red blood cells with nuclei (Fig. 10).

\section{DISCUSSION}

The results of the present study demonstrated that no remnant of the original donor blood vessels remained to participate in the vascularization of the transplanted tissue. The observations suggested that at first the host vessels opened into the clefts formed by the degeneration of grafted tissue, filling them with blood. In the first post-transplantation days, degeneration is usual $/ 3 /$, as proved by the large number of pyknotic cells that were phagocytosed in our transplants. After that, the ingrowing endothel formed sinusoids from the blood-filled lacunae and then developed further vessels from the sinusoids. Our transplants proved to be viable because when left for a longer survival period, they displayed a structure comparable to that described in the literature $/ 2,4,6,12,17 /$.

In our previous experiments in which telencephalon of 12- and 14-day-old rat embryos were transplanted in the anterior eye chamber of adult rats $19,19 /$, the survival ratio increased strikingly with the increasing age of the donor (from 11772 to $14 / 24,15.1 \%$ versus $58.3 \%$ ). The donor ages corresponded to an early and to an advanced stage of in situ telencephalic vascularization, respectively. This coincidence raised the importance of the original vascularization stage of donor brain in transplant survival. As mentioned before, several papers $/ 1,5,11-13,16,17 /$ support the opinion that the intrinsic vessels, which pre-existed in the grafted tissue before transplantation persist in the transplant and form connections with the invading host vessels. The results of the present study contradict this position and favor the other opinion $/ 14,18,20 /$ according to which the ingrowing host vessels form a completely new vascular system after the original vessels have degenerated.

One possible explanation of such paradoxical results (either obtained by us or described in the literature) is that during vascularization, the originally avascular neuroepithelium must develop a capability (because of changes of extracellular matrix components reported in $/ 15 /$, for example) to receive blood vessels. When transplanted before this 
stage of maturation, embryonic brain tissue cannot receive the extrinsic host vessels either. The presence of vessels in the donor brain is the sign of this stage of maturation, but such vessels have no direct role in transplant vascularization.

\section{ACKNOWLEDGMENTS}

The authors thank Ms. Z. Vidra for supplying time-mated pregnant animals, Ms. S. Deák for the pre- and postoperative treatment of the animals, and Mr. J. Kiss for the photographic work.

\section{REFERENCES}

1. Broadwell, RD, Charlton HM, Ebert P, Hickey WF, Villegas JC, Wolf AL. Angiogenesis and the bloodbrain barrier in solid and dissociated cell grafts within the CNS. Prog Brain Res 1990; 82: 95-101.

2. Cassel JC, Kelche C, Majchrzak M, Will BE. Factors influencing structure and function of intracerebral grafts in the mammalian brain-A review. Rest Neurol Neurosci 1992; 4: 65-96.

3. Das GD, Das KD, Braslo J, Aleman-Gomez J. Neural transplants: Volumetric analysis of their growth and histopathological changes. Neurosci Lett 1983; 41: 7379.

4. Fisher LJ, Gage FH. Grafting in the mammalian central nervous system. Physiol Rev 1993; 13: 583-606.

5. Grabowski M, Christofferson RH, Brundin $P$ Johansson BB. Vascularization of fetal neocortical grafts implanted in brain infarcts in spontaneously hypertensive rats. Neuroscience 1992; 51: 673-682.

6. Henschen A, Hoffer B, Olson L. Spinal cord grafts in oculo: Survival, growth, histological organization and electrophysiological characteristics. Exp Brain Res $1985 ; 60: 38-47$.

7. Kálmán M. Dead cells can be phagocytosed by any neighbouring cell in early developing rat brain. Int $\mathrm{J}$ Neurosci 1989; 46: 139-145.

8. Kálmán M, Kállai J, Antal S, Fülöp Z. Histological alteration in the fetal mouse cerebellum after neutron irradiation: A light and electron microscopic study. Int J Neurosci 1985; 28: 235-247.

9. Kálmán M, Tuba A. Embryonic neural tissue survival may depend upon its stage of vascularisation. Eur $\mathrm{J}$ Neurosci (Suppl) 1993; 6: 1176.

10. Karnovsky MJ. A formaldehyde-glutaraldehyde fixative of high osmolarity for use in electron microscopy. J Cell Biol 1965; 27: 137A.

11. Krum JM, Rosenstein JM. Patterns of angiogenesis in neural transplant models: I. Autonomic tissue transplants. J Comp Neurol 1987; 258: 420-434.

12. Krum JM, Rosenstein JM. Patterns of angiogenesis in neural transplant models: II. Fetal neocortical transplants. J Comp Neurol 1988; 271: 331-345.

13. Lawrence JJ, Huang SK, Raisman G. Vascular and astrocytic reactions during establishment of hippocampal transplants in adult host brain. Neuroscience 1983; 12: 745-760.

14. Mrejen S, Quinonero J, Moinard F, Ghandour S, Jacque X. Xenogeneic transplantation into newborn rodent brain-neovascularization of the graft by the host. Dev Neurosci 1992; 14: 144-152.

15. Risau W, Lemmon V. Changes in the vascular extracellular matrix during embryonic vasculogenesis and angiogenesis. Dev Biol 1988; 125: 441-450.

16. Rosenstein JM, Krum JM, Trapp BD. The astroglial response to autonomic tissue grafts. Brain Res 1989; 476 110-119.

17. Smith LM, Ebner FF. The differentiation of noncortical elements in neocortical transplants. In: Björklund A, Stenevi U, eds, Transplantation in the mammalian CNS. Amsterdam: Elsevier 11985; 81-101.

18. Stewart PA, Coomber BL. Astrocytes and the bloodbrain barrier. In Feodoroff S, Vernadakis A, eds, Astrocytes, Vol. 1. New York: Academic Press 1986; 311-328.

19. Tuba A, Kálmán M, Makarov FN. The effect of the donor vascularization stage on the fate of the intraocular telencephalic transplants. Morfolgiya (Moscow) 1996; 110: 29-32. (In Russian)

20. Zhou C-F, Lindsay RM, Lawrence JM, Raisman G. Extent of survival and vascularization of adult superior cervical sympathetic or nodose ganglia transplanted into the septal nuclei or choroid fissure of adult rats. Neuroscience 1986; 17: 803-815. 

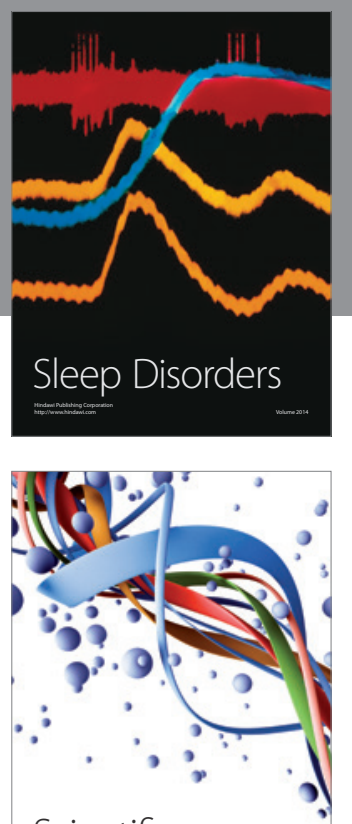

Scientifica
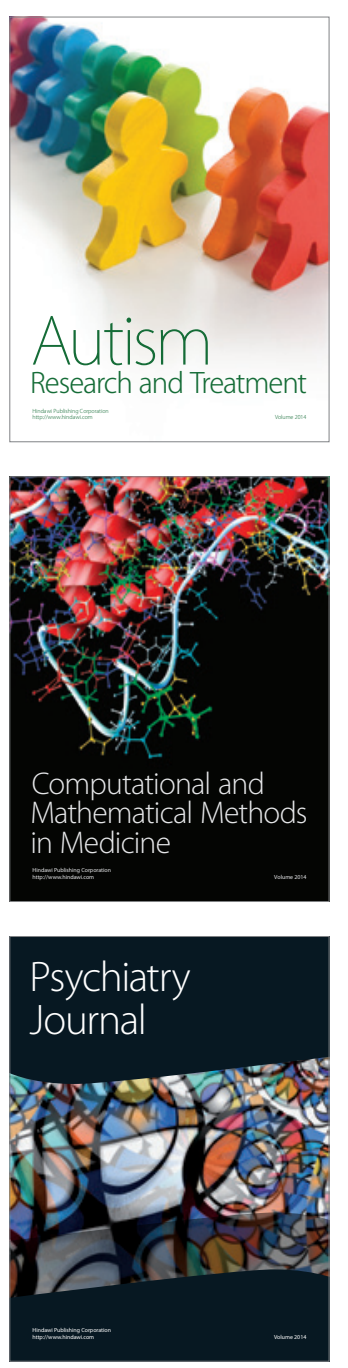
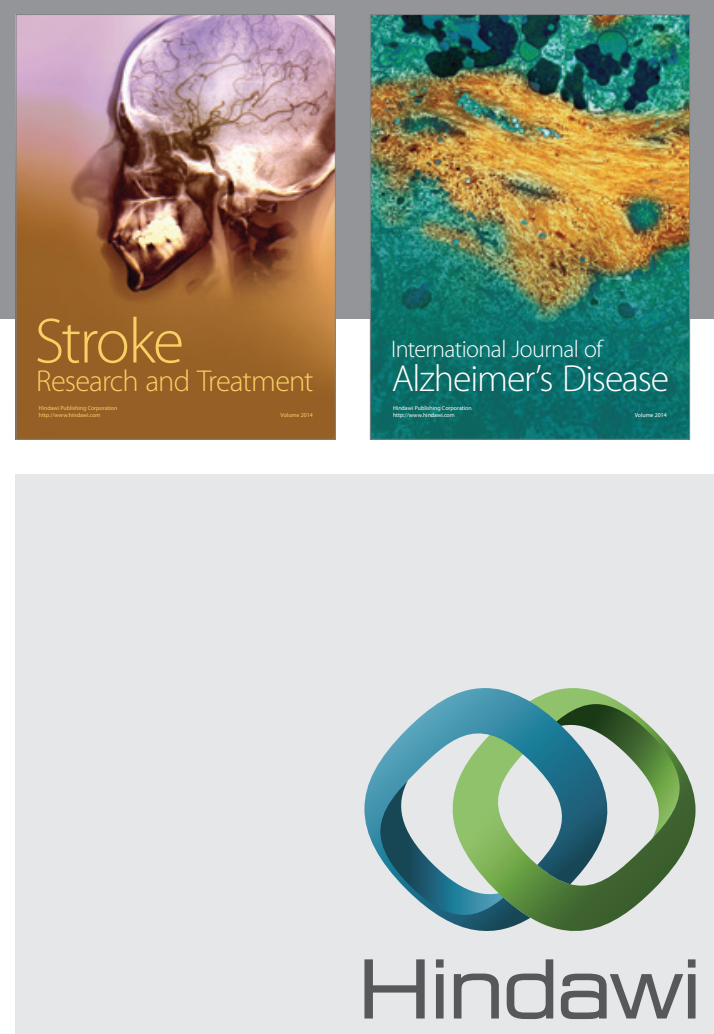

Submit your manuscripts at

http://www.hindawi.com
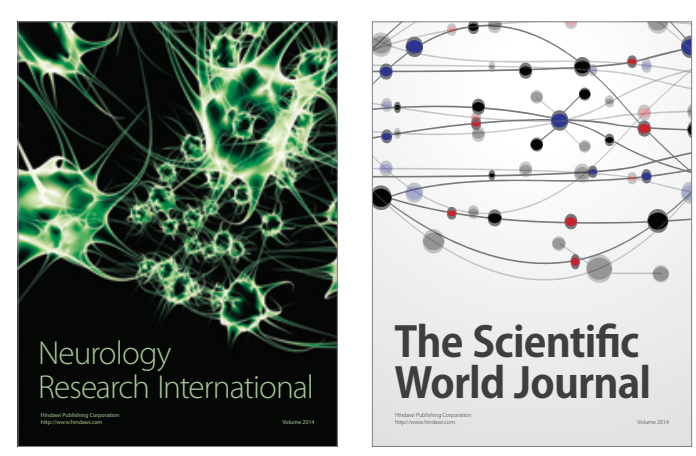

The Scientific World Journal

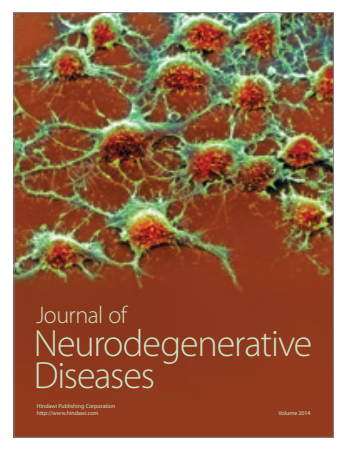

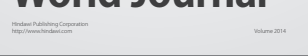

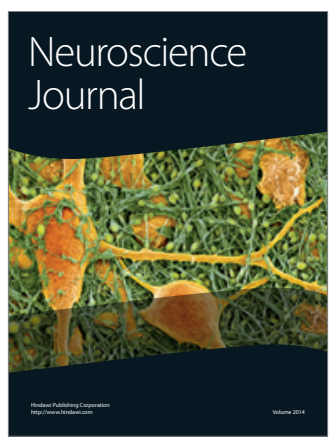

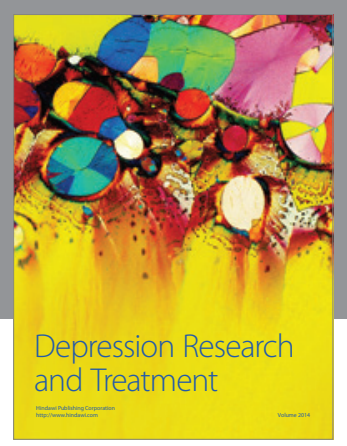
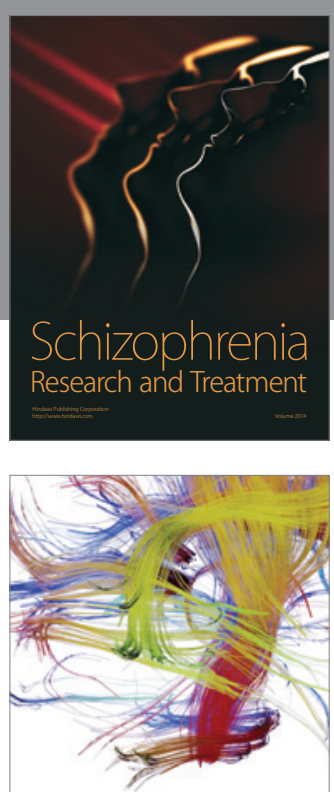

Brain Science

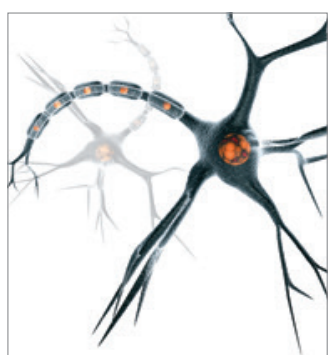

Neural Plasticity
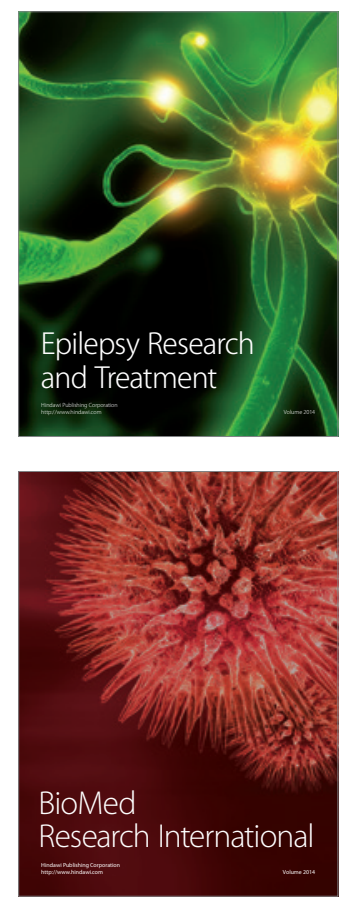

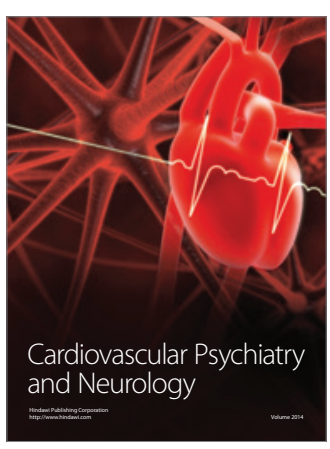

Parkinson's

Disease
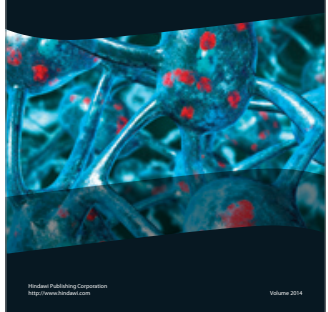